\title{
A composição em Tupí
}

\author{
Aryon Dall'Igna Rodrigues
}

As pessoas que, no Brasil, se têm dedicado ao estudo da língua Tupí, têm-se limitado, em geral, a travar conhecimento com uma série de vocábulos isolados do idioma indígena e, com esse material, a empreender a interpretação de antropônimos, topônimos, zoônimos, fitônimos, etc. Têm pretendido, assim, fazer etimologia. Têm-lhes falecido, entretanto, todos os elementos para conseguir qualquer resultado positivo nessa empreitada, que fascina a todos, desde as pessoas de cultura universitária até ao mais analfabeto dos homens do povo. O gosto pela "etimologia" das palavras indígenas é generalizado não só no Brasil, mas em toda a América do Sul, e vem de longe, de muito longe: já nos primeiros anos da colonização, procuravam os portugueses descobrir os significados dos nomes nativos. Trata-se da curiosidade natural ao homem de explicar o desconhecido; curiosidade que é a mãe das ciências e a mãe da própria etimologia, mas que, nem por isso, conduz, assim sem mais nem menos, à ciência etimológica. Tem falecido aos "etimologistas" que temos tido, embora entre eles se contem alguns nomes respeitabilíssimos da cultura brasileira e da cultura mundial, os elementos necessários para empreender um verdadeiro trabalho etimológico. Tem-lhes faltado conhecimento de duas coisas logicamente indispensáveis para estabelecer o étimo de qualquer palavra: a língua de que tal palavra provém e a própria etimologia.

A etimologia, como ciência linguística bem caracterizada, tem seu método e seu rigor muito próprios. Como diz muito acertadamente o prof. Rodrigo de Sá Nogueira, "nas suas pesquisas, o etimologista não pode proceder de qualquer modo: há normas, a que deve obedecer; há precauções, que deve tomar; há fatos científicos, que não deve olvidar; e há critérios, que lhe convém criticar" (Crítica Etimológica, $1^{\circ}$ vol., Lisboa, 1949). Quais essas normas, quais essas precauções, quais esses fatos científicos, quais esses critérios, poderá o 
leitor ver na mencionada obra do mesmo linguista português, a qual desde logo recomendamos aos estudantes brasileiros, que sempre lerão com o máximo proveito as "generalidades sobre o problema etimológico", às pp. 8-46, breve, mas excelente metodologia a todos acessível.

O etimologista deve ter conhecimentos seguros de fonética histórica e de semântica, mas, ainda quando bem aparelhado com esses conhecimentos imprescindíveis, não poderá realizar trabalho sério se não tiver conhecimento da língua com que vai trabalhar. Isto é óbvio. E é o que se tem dado com os que, até aqui, têm pretendido determinar étimos de palavras portuguesas de origem indígena. Ainda os mais renomados estudiosos da onomástica brasileira, como Martius e Teodoro Sampaio, não conheciam (ou conheciam muito superficialmente) a língua de que mais necessitavam em seus estudos: o Tupí antigo. E, nos poucos casos de conhecimento da língua, como é o do venerável Batista Caetano, fazia-lhes falta toda noção de verdadeira etimologia. Aplica-se isto não só a Batista Caetano, em cuja época a etimologia ainda não possuía os métodos que hoje lhe dão segurança e rigor científicos, mas igualmente aos estudiosos modernos.

Desta situação negativa resulta que não há nenhum estudo seguro de etimologia de palavras brasileiras provindas dos idiomas indígenas. Se há étimos determinados com acerto, são aqueles que se evidenciam por si mesmos, porque as palavras não sofreram alterações fonéticas ou semânticas apreciáveis. Fora desses casos, o que há são tentames feitos ao acaso, tateamentos por assim dizer. Daí ser tão frequente poder-se arrolar, não só nas obras de diferentes autores, mas ainda nas de um mesmo, dois, três, quatro ou mais étimos propostos para uma mesma palavra incorporada ao português. A fantasia tem contribuído em larga escala na feitura de quase todos esses trabalhos de exegese etimológica. Porque a etimologia, como disse Dauzat, é sem dúvida o mais sedutor aspecto da linguística, todos os que se apanham com um vocabulário indígena nas mãos entregam-se afoitamente à tarefa de "fazer etimologia"...

Agora, porém, é tempo já de pôr de lado toda fantasia e de preparar-se para a consecução de resultados seguros e definitivos. Em nosso país já se vai preparando o ambiente para o empreendimento de verdadeiros estudos de etimologia. Por um lado, as Faculdades de Filosofia, instituições da mais alta significação para o futuro da cultura nacional, ministram os conhecimentos linguísticos de fonética e de semântica, dos quais não pode prescindir o etimologista; por outro lado, começam a firmar-se, nas mesmas Faculdades de Filosofia, os estudos da língua Tupí antiga, que constitui a principal fonte dos brasileirismos de procedência nativa.

Um dos aspectos do Tupí antigo mais importantes para quem se quiser dedicar à investigação etimológica, é sem dúvida o processo de composição 
nesta língua predominantemente incorporante. De igual importância é, também, a derivação por meio de afixos; desta, porém, não trataremos aqui, mas dedicamos este artigo apenas à composição, de que procuramos fazer uma primeira tentativa de sistematização.

Para bem compreender o que se vai expor a propósito da composição, é necessário que tenha o leitor algumas noções de fonética e de morfologia tupís, as quais resumimos abaixo, dentro do estritamente indispensável a este estudo.

\section{Observações fonéticas ${ }^{1}$}

1) quando se encontram duas consoantes, dá-se a queda da precedente;

2) se a consoante precedente (que cai) for nasal ( $m b, n d, n g, m, n)$, nasalizar-se-á a consoante seguinte;

3) $k$ nasaliza-se em $n g, t$ em $n d, p$ em $m b, s$ em $n d, r$ em $n$;

4) igualmente se nasaliza a consoante precedida por vogal nasal;

5) a semivogal $i$, precedida por vogal nasal, se encontrar-se com outra vogal, mudar-se-á em $\tilde{n}$;

6) se $m$ e $n$ forem seguidos por vogal tônica, mudar-se-ão em $m b$ e $n d$ respectivamente;

7) $s$, quando precedido por $i$, muda-se em $s$.

\section{Observações morfológicas}

1) os temas tupís apresentam dois aspectos: nominal, em que funcionam como substantivos; verbal, em que funcionam como verbos; ambos diferem morfologicamente só quando o tema termina em consoante, caso em que recebe a desinência - $a$ no aspecto nominal;

2) dividem-se os temas em duas classes: a classe I compreende os temas que não recebem prefixo de relação, a classe II abrange os temas que recebem prefixo de relação; o prefixo de relação é $r$ - e ocorre sempre que o tema da classe II é precedido por um substantivo (no aspecto nominal) ou pelos pronomes da $1^{\mathrm{a}}$ e $2^{\mathrm{a}}$ pessoas da $1^{\mathrm{a}}$ classe (os temas de uma e outra classe são indicados pelos números I e II que os seguem);

3) aos temas que designam animais, elementos da natureza e outros seres que não podem ser determinados por um possessivo, não se aplica a divisão nessas duas classes; por isso não são eles acompanhados de qualquer indicação;

1. Por razões de tipografia, deixou-se de fazer distinção entre as semivogais $i$ e $u$ e as vogais $e$ e $u$. e nasal foi representado por $e^{n}$. $s$ representa a fricativa palatal surda (ch português). $\mathrm{O}$ apóstrofo junto à letra $y$ substitui o acento agudo. 
4) os temas, que designam seres passíveis de relacionar-se a homens, possuem, no aspecto nominal, uma forma absoluta, a qual indica essa relação com seres humanos;

5) nos temas da classe II, a forma absoluta é caracterizada pelo prefixo $t$-; em alguns, porém, forma-se pela perda da vogal inicial e noutros é indistinta;

6) nos temas da classe I iniciados por $p$ é caracterizada a forma absoluta pela nasalização do $p$, que se muda em $m b$ ou $m$; nos demais temas desta classe é indistinta;

7) no presente estudo, os componentes são apresentados na forma temática (indicada pela abreviatura t.); os compostos, se substantivos, apresentam-se no aspecto nominal, se verbos, no aspecto verbal.

\section{A composição}

1. Distinguem-se duas espécies de composição:

a) composição propriamente dita,

b) incorporação.

2. A composição propriamente dita é aquela em que se reúnem dois ou mais temas para formar um novo substantivo, que se comporta na frase como qualquer substantivo simples. Os compostos são de dois tipos: determinativos e atributivos.

3. Os compostos determinativos são constituídos por temas de substantivos, dos quais o primeiro é o determinante e o segundo, o determinado. Exemplos:

t. pirá "peixe" + t. ñandy' I "óleo" = piráñandy" "óleo de peixe"

t. uúb II "flecha" + t. urú II "recipiente" = uúburú "aljava"

t. iperú "tubarão" + t. ky'b "piolho" = iperúky'ba "piolho de tubarão" (peixe-piolho, Echenei ssp.)

t. ypé I "casca de árvore" + t. ygár I "canoa" = ypéygár "canoa de casca"

t. mberú "mosca" + t. ay’r II "filho" = mberúay'ra "vareja"

t. mén I "marido + t. sy' I "mãe" = mendy" "sogra"

t. mén I "marido" + t. úb II "pai" = méndúba "sogro"

t. aty' II "esposa" + t. úb II "pai" = atúúba (forma absoluta tatúúba) "sogro"

t. ygár I "canoa" + t. embé II "lábio" = ygárembé "bordos da canoa".

A um composto determinativo pode reunir-se novo tema, que o determina por sua vez; p. ex.: atá II "fogo" + t. endy" II "luz" = atáendy" "luz do fogo" + t. urú II "recipiente" = atáendy'urú (forma absoluta tatáendy'urú) "candieiro".

4. Nos compostos atributivos o primeiro elemento é o determinado e o segundo o determinante; este exprime um atributo daquele. $\mathrm{O}$ determinado sempre é um tema de substantivo, o determinante pode ser um tema de subs- 
tantivo ou um tema verbal. Quando o determinante é tema do substantivo, o composto pode ser apositivo ou possessivo.

5. É apositivo o composto em que o determinante funciona como simples aposto do determinado. Exemplos:

t. aipí I "aipim" + t. iurumú I "abóbora" = aipíiurumú "aipim-abóbora" (Manihot utilissima L., var.)

t. ybá I "fruta" + t. kamusí I "pote" = ybákamusí "fruta-pote"

t. guyrá "pássaro" + t. iaguár "jaguar" = guyráiaguárá "pássaro-jaguar"

t. ybyrá I "cerca de paus" + t. pataguí I "estrado" = ybyrápataguí "cerca-estrado i. é, semelhante a estrado"

t. mbaé I "coisa" + t. atá II (abs. tatá) "fogo" = mbaétatá "coisa-fogo, coisa que é fogo, o fogo-fátuo"

t. iaguár "cão" + t. eimbáb II (abs. mimbába) "animal doméstico, xerimbabo" = iaguámimbába "cão doméstico, cão que é xerimbabo"

t. ybá I "fruta" + t. emetár II (abs. metára) "tembetá" = ybámetára "fruta-tembetá"

6. No composto possessivo indica-se que o determinado possui ou contém em si o determinante, ou que tem o determinante com alguma particularidade especial. Exemplos:

t. andyrá "morcego" + t. ák I "chifre" = andyrááka "morcego que tem chifre"

t. guamaiakú "baiacu" + t. apé I "casca" = guamaiakúapé "baiacu que tem casca" (ostracião, Lactophrys trigonus (L))

t. guyrá "ave" + t. akángatár I "acangatara" = guyráakángatára "ave que tem acangatara" (Guira guira (Gmelin))

t. abá "pessoa" + t. obá II "rosto" = abáobá "pessoa que tem o rosto com alguma particularidade"

t. akará "acará" + t. ãi II "dente" = akaráãia, akaráãña "acará que tem dentes com alguma particularidade" (caranha, Mesopryon aya C. \& V.)

Num composto possessivo o determinante poderá já ser, por sua vez, um composto por incorporação do epíteto (cf. § 9):

t. pirá "peixe" + akámukú comp. de t. akáng I "cabeça" + t. pukú I "comprido" = piráakámukú "peixe que tem cabeça comprida" (espécie de bagre)

t. káb "vespa" + obáiúb comp. de t. obá II "cara" + t. iúb I "amarelo" = kábobáiúba "vespa que tem cara amarela"

t. pirá "peixe + iurúmembék comp. de t. iurú I "boca" + t. membék I "mole" = piráiurúmembéka "peixe que tem boca mole" (boca-mole, Archoscion petranus Mir. Rib.)

t. guamaiakú "baiacu" + átíng comp. de t. á I "cabeça" + t. tíng I "branco" = guamaiakúátínga "baiacu de cabeça branca" (Chilomycterus sp.) 
7. Compostos atributivos em que o determinante é um tema verbal:

t. teiú "teju" + t. ñán I "correr" = teiúñána "teju que corre, teju corredor" (Teius teiu teiu (Daud.))

t. pirá "peixe" + t. bebé I "voar" = pirábebé "peixe voador" (Trigla volitans $L$.)

t. guyrá "ave" + ñeéngatú intensivo do t. ñeéng I "cantar" = guyráñeéngatú "ave que canta bem, ou que canta muito" (canário da terra, Sicalis flaveola brasiliensis (Gmelin))

t. ybyrá I "madeira" + t. pararáng I "rodar pelo chão" = ybyrápararánga "madeira que roda pelo chão, i. é, roda de madeira"

t. itá "pedra, metal" + t. ekobé II "viver" = itáekobé "metal que vive, metal vivo, i. é, mercúrio"

t. $y b y$ " "terra" + t. ám I "estar em pé, estar levantado" = yby'áma "terra levantada, barranco".

8. A incorporação é a composição que consiste na reunião íntima do adjetivo epíteto ao substantivo ou ao verbo que qualifica, ou do substantivo objeto direto ao verbo transitivo. Há, pois, dois tipos de incorporação: incorporação do epíteto e incorporação do objeto.

9. Na incorporação do epíteto, o tema do adjetivo segue o do substantivo ou do verbo que ele qualifica, com o qual constitui um todo que se comporta como qualquer substantivo ou qualquer verbo simples, respectivamente. Exemplos:

t. iurú I "boca" + t. membék I "mole" = iurúmembéka "boca mole"

t. mberú "mosca" + t. oby' II "verde" = mberúoby" "mosca verde" (Ornidia obesa (Fabr.))

t. kaá "erva" + t. pomóng I "viscoso" = kaápomónga "erva viscosa" (Plumbago scandens $L$.)

t. kaá "erva" + t. péb I "chato, plano" = kaápeba "erva chata" (erva-de-Nossa-Senhora, Cissampelos pareira L.)

t. ybyrá I "madeira" + t. een II "doce" = ybyráeen "madeira doce" (Lucuma glycyphloea Mart. \& Eichl.)

t. ybyrá I "madeira" + t. pytáng I "pardo, vermelho" = ybyrápytánga "madeira vermelha" (pau-brasil, Cesalpinea echinata Lam.)

t. pitúb I "almagrar" + t. piráng I "vermelho" = pitúpiráng "almagrar de vermelho"

t. ñeéng I "falar" + t. atã II "duro" = ñeéngatã "falar duro, falar ardegamente"

t. mombeú I "dizer" + t. poráng I "bonito" = mombeúporáng "dizer bonito,

i. é, louvar". 
A um composto por incorporação do epíteto pode incorporar-se, ainda, outro epíteto, que qualifica o composto anterior como um todo; p. ex.: t. itá I "metal" + t. iúb I "amarelo" = itáiúb (aspecto nominal itáiúba "metal amarelo, i. é, ouro, dinheiro") + t. tíng I "branco" = itáiútínga "dinheiro branco, i. é, dinheiro de prata" (lit. "metal-amarelo branco").

10. Na incorporação do objeto, o tema do substantivo precede o tema verbal transitivo. Se o substantivo incorporado estiver na forma absoluta, ou se for inconjugável, ou se se empregar indeterminadamente, o todo resultante será um verbo intransitivo; em caso contrário, i. é, se for conjugável, não estando na forma absoluta, será um verbo transitivo. Exemplos:

t. obá II (abs. tobá) "rosto" + t. epiák II "ver" = tobáepiák intr. "ver rostos humanos"

t. pysá I "rede de pesca" + t. eity'k II "lançar" = pysáeity'k intr. "lançar rede" t. obá II "rosto" + t. peték I "dar palmada em" = obápeték trans. "dar bofetada em"

t. embey'b II "borda" + t. kyty' I "cortar" = embeykyty' trans. "aparar"

t. kó I "roça" + t. moñáng I "fazer" = kómañáng trans. "fazer roça para (alguém)"

t. posáng I "remédio" + t. nóng I "pôr" = posánóng trans. "pôr remédio, curar".

\section{Bibliografia}

Anchieta, Joseph de, Arte de Gramática da Lingua mais Usada na Costa do Brasil, ed. da Bibl. Nacional do Rio de Janeiro, Rio, 1933.

Dall'Igna Rodrigues, Aryon, Compêndio de Gramática do Tupi Antigo, ms. inédito.

Figueira, Luís, Arte de Gramática da Língua Brasílica, ed. de E. Allain, Rio, 1880.

Marcgrave, Jorge, História Natural do Brasil, trad. de J. P. Magalhães, ed. do Museu Paulista, S. Paulo, 1942.

Piso, Guilherme, História Natural do Brasil Ilustrada, trad. de Alexandre Correia, S. Paulo, 1948.

Vocabulário na Língua Brasílica, manuscrito português-tupi do século XVII, coordenado e prefaciado por Plínio Ayrosa, S. Paulo, 1938. 